\title{
Battling Bias: Can Two Implicit Bias Remedies Reduce Juror Racial Bias?
}

\author{
Christine L. Ruva \\ Elizabeth C. Sykes \\ Kendall D. Smith \\ Lillian R. Deaton \\ Sumeyye Erdem \\ Department of Psychology, University of South Florida
}

Angela M. Jones

School of Criminal Justice and Criminology, Texas State University San Marcos

\section{Author Note}
Christine L. Ruva
https://orcid.org/0000-0001-8911-786X
Elizabeth C. Sykes
https://orcid.org/0000-0002-4180-3251
Kendall D. Smith
https://orcid.org/0000-0002-6922-3603
Lillian Deaton
https://orcid.org/0000-0001-8766-5758
Sumeyye Erdem
https://orcid.org/0000-0001-9972-5236
Angela M. Jones
(iD https://orcid.org/0000-0001-7605-4206

Correspondence concerning this article should be addressed to Christine L. Ruva, Department of Psychology, University of South Florida Sarasota-Manatee, Sarasota, FL 34243. Email: ruva@usf.edu

\section{Author Note}

The studies' data, stimuli, and measures are available in the OSF Project: https://osf.io/k5fpa/?view_only=9880bbc7e5fc47b6be7748995d2656b8

Anonymous OSF Project link for peer review.

This research was supported by an award from the Chancellor's Professional Support Initiative at the University of South Florida Sarasota-Manatee. This funding source had no other role other than financial support. 


\begin{abstract}
Two studies examined the effectiveness of the Unconscious Bias Juror (UBJ) video and instructions at reducing racial bias in Black and White mock-jurors’ decisions, perceptions, and counterfactual endorsement in a murder (Study 1; $N=554$ ) and battery (Study 2; $N=539$ ) trial. Participants viewed the UBJ video or not, then read pretrial instructions (general or UBJ), a trial summary, and posttrial instructions (general or UBJ). In Study 1, juror race moderated the effect of defendant race on verdicts, culpability, and credibility. White, but not Black, jurors demonstrated greater leniency toward Black defendants for verdicts, culpability, and credibility. The UBJ video moderated the effect of defendant race on murder counterfactual endorsement. Only when the video was absent was jurors' counterfactual endorsement higher for the White versus Black defendant, which mediated the effect of defendant race on White jurors' verdicts. In Study 2, White jurors were more lenient regardless of defendant race. Instructions and juror race moderated the video’s effect on credibility ratings. The video only influenced Black jurors’ credibility ratings. In conclusion, the debiasing interventions were ineffective in reducing racial bias in jurors' verdicts. However, they do impact aspects of juror attribution and may be effective with modification.
\end{abstract}

Keywords: implicit bias remedies, racial bias, juror bias, jury instructions, crime type 


\section{Battling Bias: Can Two Implicit Bias Remedies Reduce Juror Racial Bias?}

On April 19, 2021, Judge Peter Cahill addressed the jury in the trial of Derek Chauvin, a White police officer charged with murder for the death of George Floyd, a Black man. His closing instructions centered on the topic of implicit or unconscious bias. Implicit bias derives from automatic stereotypes and attitudes that are activated beyond a person's conscious awareness (Wilson et al., 2000). Judge Cahill’s statement to the jury included:

Some biases we are aware of, and others we might not be fully aware, which is why they are called implicit or unconscious biases. No matter how unbiased we think we are, our brains are hardwired to make unconscious decisions. We look at others and filter what they say through the lens of our own personal experience and background (CBS, 2021). Implicit bias is a concern for the legal system as jurors’ unconscious preferences can alter the outcome of a trial (Kang et al., 2012). Currently, the legal system does not have a uniform and effective way to address implicit racial bias in jurors (Su, 2020). Previous court remedies for juror bias include "for cause” and "peremptory challenges," which rely on attorneys recognizing bias in jurors during the voir dire process ( $\mathrm{Su}, 2020)$. However, people are motivated to hide their bias to appear unprejudiced (Plant \& Devine, 2001). Furthermore, the peremptory challenge can be abused on the basis of race (Batson v. Kentucky, 1986; Flowers v. Mississippi, 2019; see O’Brien \& Grosso, 2020 for review) and objections to race-based preemptory challenges are rarely successful (Melilli, 1996; Sommers \& Norton, 2007). Importantly, this remedy is only meant to address explicit bias. The Western District of Washington recently implemented an Unconscious Bias Juror (UBJ) video and instructions meant to address implicit bias in jurors. The present study tested the effectiveness of these interventions in combatting racial bias. 


\section{Implicit Bias Remedies}

According to the flexible correction model, to overcome ingrained biases, jurors need to be aware of their bias, motivated to correct it, and know the direction of such bias (Wegener \& Petty, 1997; Wilson et al., 2002). If a juror is unaware of the bias (i.e., bias blind spot) or lacks the motivation or tools needed to correct it, then the bias will persist. Attempts at correction do not always remedy the bias - they can intensify the bias or result in overcorrection (Wegener \& Petty, 1997).

Over the last two decades, considerable research has explored remedies to combat implicit bias. For example, instructing White participants to imagine a Black man's feelings in a situation involving racial discrimination (perspective taking) showed a greater reduction in prejudice compared to participants given instructions to remain objective or no instructions (Dovidio et al., 2004). Reflective thinking has also shown promise at reducing implicit racial bias in a trial setting. Schuller et al. (2009) tested the efficacy of the current challenge for cause procedure in Canada, which is close ended (asks jurors if their ability to judge a defendant would be affected) versus a modified reflective format (asks jurors how their ability to judge a defendant would be affected). Only the reflective strategy reduced racial bias in jurors' guilt assessments. Finally, a comparison of 17 implicit racial bias interventions found that counterstereotypical exemplars (e.g., participants imagine a White perpetrator assaults them and they are then rescued by a Black man who witnessed the assault) were most effective at reducing bias in a sample of non-Black participants (Calanchini et al., 2020).

Along with bias awareness, effective interventions must (1) decrease blameworthiness (accomplished by suggesting that everyone holds these biases), and (2) increase perception that bias can be remedied, which can reduce defensiveness and associated self-protective behaviors, 
as well as backlash (e.g., increase bias or decrease motivation to judge fairly; Vitriol \& Moskowitz, 2021). Additionally, effective bias intervention generates personal responsibility and culpability for bias—conveying that while bias is pervasive it is nonetheless unacceptable (Vitriol \& Moskowitz, 2021). The implication that bias is normative could decrease personal responsibility and motivation to correct.

\section{Unconscious Bias Juror (UBJ) Video and Instructions}

The present studies test the effectiveness of the UBJ video and instructions, developed by the Western District of Washington (2017), at reducing implicit racial bias in juror decision making. Currently, this UBJ video is shown during juror orientation in Washington, Rhode Island (U.S. District Court, District of Rhode Island, n.d.), and California (U.S. District Court, Northern District of California, n.d.) as a form of implicit bias training. In the video, a US district judge and two attorneys define unconscious bias, provide examples (e.g., viewers may have perceived the judge as "smart” and “impartial,” or as “tough” and “scary”), and make appeals to egalitarian values (e.g., “everyone should be judged fairly”). The video informs viewers that everyone has unconscious biases and provides suggestions on how to correct for bias in the courtroom (e.g., take “time to examine what's influencing our decisions”). Such language meets the requirements identified by Vitriol and Moskowitz (2021) for effective interventions by decreasing moral blameworthiness and suggesting that these biases can be controlled, which reduces defensive responding to implicit bias feedback. Further, some evidence suggests viewing an instructional video reduces implicit bias in the short-term (Morewedge et al, 2015;

Salmanowitz, 2018; Shaw et al., 2016), as well as makes race more salient.

The UBJ instructions consist of pretrial and posttrial instructions that explain what unconscious bias is ("stereotypes” that "may be expressed without... awareness") and how it can 
affect the evaluation of evidence, perceptions of witnesses, and decision making. Like the video, the instructions increase awareness and suggest jurors are responsible for their biases ("you must avoid bias”); however, they do not provide jurors with methods for controlling them. Moreover, they lack aspects to decrease juror defensive responding such as indicating that everyone holds these biases and that biases are controllable (Vitriol \& Moskowitz, 2021). Thus, while a sense of personal responsibility is beneficial for decreasing bias, this aspect is left unaddressed.

At present, the video and instructions are given to every juror in the U.S. District Court, Western District of Washington. However, the mandate of this proposed remedy in certain jurisdictions has been controversial. Multiple judges have denied their use, either on the basis that it would create greater bias or due to a lack of precedent (Gayla, 2017; Innocence Staff, 2018). Yet, despite no empirical research suggesting this remedy reduces racial bias, courts in Oregon, Connecticut, Michigan, and Texas have created similar videos.

More broadly, only two published studies attempted to evaluate implicit bias jury instructions (Elek \& Agor, 2014; Lynch et al., 2022). However, neither were able to test the instructions’ effectiveness because mock jurors did not display any racial bias. Researchers have investigated the efficacy of other types of jury instructions on bias. For example, instructions which defined legal terms without legalese reduced racial bias toward Black defendants in a capital trial compared to a standard instruction (Shaked-Schroer et al., 2008). However, instructions to disregard inadmissible evidence, including pretrial publicity, are generally ineffective (Steblay et al., 2006) and their use may backfire, causing more bias (Lieberman \& Arndt, 2000). Thus, research on instructions to reduce bias indicate limited effectiveness. That said, both the UBJ video and instructions in combination may more effectively remind jurors to recall their unconscious bias training and remain impartial (Su, 2020). 


\section{Defendant Race and Juror Decisions}

The presence of racial bias in the criminal justice system necessitates debiasing mechanisms to protect a defendant's right to a fair trial. Yet the influence of defendant race on jurors' decisions is unclear. The first meta-analysis on racial bias did not find an effect on jurors' guilt assessments or sentences (Sweeney \& Haney, 1992). In contrast, a subsequent metaanalysis found a small effect of racial bias such that White jurors gave Black defendants longer sentences than White defendants (Mazzella \& Feingold, 1994). The type of crime also moderated sentence length. Negligent homicide cases resulted in longer sentences for Black defendants and fraud cases resulted in longer sentences for White defendants.

Mitchell and colleagues (2005) found a small effect of defendant race on jurors’ verdict decisions, which was moderated by participant race, type of measure, jury instructions, and study date. Racial bias was more robust for Black jurors (against White defendants), when guilt was measured continuously (as opposed to dichotomously), jury instructions were absent, and studies were from the 1970s. Black jurors also showed greater leniency towards Black defendants than White defendants in sentencing decisions. Compared to students, racial bias in community samples was stronger. Similarly, the most recent meta-analysis found a small overall effect of defendant race as an outgroup bias on juror guilt judgements (Devine \& Caughlin, 2014). This effect was greatest for Black jurors in a case with a Black or White defendant, followed by White jurors in a case with a White or Hispanic defendant. These meta-analyses suggest that racial bias in jurors’ decisions is complex and can be influenced by a variety of factors.

Additionally, jurors associate defendant race with the type of crime committed (e.g., White defendant with fraud and Black defendants with negligent homicide; Mazzella \& Feingold, 1994), thus moderating any effect of race on jurors’ decisions. Defendants charged 
with crimes that are stereotypically congruent with their race are more likely to be found guilty and treated more punitively than defendants charged with non-stereotypical crimes (Gordon \& Anderson, 1995; Jones \& Kaplan, 2003). Further, jurors give more weight to incriminating evidence when defendant race and crime are stereotypically congruent (Smalarz et al., 2018).

Some crimes such as intimate partner violence (IPV), however, are not clearly associated with a specific race or ethnicity. For example, Shernock and Russell’s (2012) review of IPV research concludes that there is "impartial treatment toward racial/ethnic minorities regarding issuance of protection orders, arrest, and prosecution” (p. 501). In contrast, Cramer’s (1999) review of actual cases found that White male defendants (as opposed to non-White) had a greater likelihood of domestic violence conviction. These findings demonstrate the importance of examining race across multiple crime types (e.g., spousal murder vs. battery).

\section{Aversive Racism Theory and Social Identity Theory}

Because jurors may provide race-neutral justifications to implicitly discriminate by race, theory can further explain the relationship between crime type and defendant race. Aversive racism theory is based on the premise that White people are guided by prevailing egalitarian views to appear impartial when making conscious decisions despite still harboring unconscious stereotypes about Black people (Dovidio et al., 1998; Dovidio \& Gaertner, 2004). Egalitarian views may be motivated by social norms to appear unprejudiced (Dovidio et al, 1998; Dovidio \& Gaertner, 2004; Plant \& Devine, 1998). Thus, racial bias is likely suppressed when race is brought to the forefront (e.g., a crime motivated by race; Sommers \& Ellsworth, 2000, 2001) so that decisions are congruent with explicit beliefs. In the aversive racism paradigm, the mechanism for decreasing bias is the activation of egalitarian views (Dovidio et al., 2004). However, in an ambiguous trial, a lack of solid evidence opens the door for jurors to justify 
decisions based on non-race factors, similar to attorneys seeking to remove jurors of color during the voir dire process (Batson v. Kentucky, 1986; see O’Brien \& Grosso, 2020 for review). These non-race factors could include crime type or socioeconomic status (Esqueda et al., 2008). In fact Devine and Caughlin (2014) found a greater overall effect of socioeconomic status than race. These are two examples of factors stereotypically associated with race that may be used unconsciously to justify race-based discrimination. Importantly, both the UBJ video and instructions are premised upon making implicit bias salient to increase effortful processing.

Social identity theory builds on the concept that stereotypes are shared beliefs, and that shared meaning facilitates the distinction of in-groups and out-groups (Abrams \& Hogg, 2004). To maintain positive self-esteem, people exhibit favoritism towards in-group members (Lapinski \& Mastro, 2001; Turner et al., 1979) and discriminate against the out-group (Abrams \& Hogg, 2004). Notably, Black jurors show greater rates of in-group favoritism than White jurors (Devine \& Caughlin, 2014), possibly due to social identity as well Black jurors’ heightened awareness and sensitivity to bias against Black defendants (Kahn \& Martin, 2020; Weitzer \& Tuch, 2005). Moreover, social identity theory suggests that jurors favor defendants of the same race by finding them guilty less often when evidence is ambiguous. When evidence is clear, jurors may respond harsher to in-group than out-group members (i.e., the black sheep effect) to distance the group from unreputable behavior and preserve self-esteem (Van Prooijen, 2006). Thus, in-group favoritism will most likely prevail in ambiguous trials.

\section{Counterfactual Thinking and Jury Decision Making}

The present studies explore the mediating role of counterfactual thinking (Alvarez \& Miller, 2016; Ruva \& Sykes, 2022). Counterfactual thinking, or “what if” thinking, is defined as imagining aspects of a past situation to be different, and how that difference influences an 
outcome (Roese, 1997; Roese \& Olson, 1995). In order to determine guilt, jurors are asked to participate in counterfactual thinking (e.g., If the actions of the defendant were different the victim would not have suffered these consequences; Spellman \& Kincannon, 2001) and use their event norm to evaluate the cause of an event after its occurrence (Kahneman \& Miller, 1986). Mutability, or how easily an event could have been changed, impacts the availability of counterfactual alternatives such that greater mutability increases the generation of counterfactual alternatives (Kahneman \& Miller, 1986). Abnormal events have greater mutability than normal events, as it is easier to imagine an action that is abnormal being altered. For example, a gun fired inside a suburban home leading to the death of a person is out of the ordinary. Thus, individual jurors will use their own set of norms to determine mutability and ultimately how to causally interpret these circumstances. Specific to racial bias, racial stereotypes may impact the degree of mutability an individual assigns to the actions of the defendant. For example, Black defendants are stereotypically associated with battery (Schuller et al., 2009). Therefore, jurors that endorse this stereotype may generate fewer counterfactual alternatives when evaluating a Black defendant accused of battery.

\section{Present Studies}

Across two studies that varied in crime type, we examined the effectiveness of the UBJ video and instructions at reducing racial bias in mock-juror decisions (i.e., verdicts) and impressions (i.e., defendant credibility, culpability, and counterfactual endorsement). Different trial types were used since crimes congruent with racial stereotypes accrue greater bias (Jones \& Kaplan, 2003). Although spousal murder is not clearly associated with any race (Shernock \& Russell, 2012), battery is stereotypically associated with Black defendants (Schuller et al., 2009). To give further insight into the relationship between crime type and race, the studies manipulated 
defendant race (Black vs. White) and recruited approximately equal numbers of Black and White mock jurors. Finally, although the UBJ video and instructions are given together in the Washington court system, they were manipulated individually to investigate the effectiveness of each component. While the UBJ video contains more elements that aid in debiasing (Vitriol \& Moskowitz, 2021) and addresses aspects of the flexible correction model (Wegener \& Petty, 1997), the UBJ instructions may serve as a necessary reminder of this information. These reminders at key points during the trial process may increase race salience and promote egalitarian views, as well as a desire to appear impartial, which are all important aspects of aversive racism theory. Therefore, the individual manipulations of the UBJ remedies may reveal effective components of debiasing.

\section{Hypotheses}

H1. We expect an interaction between defendant race and juror race on verdicts, culpability, and credibility. Jurors who are the same race as the defendant will be less likely to find the defendant guilty and will rate him lower in culpability and higher in credibility.

H2. We expect an interaction between defendant race, juror race, and the UBJ video on verdicts, culpability, and credibility. The UBJ video will have the greatest impact on racial bias for White jurors. Unlike their no-video counterparts, White jurors who receive the UBJ video will not differ in their verdicts, culpability, and credibility ratings as a function of defendant race. Because of Black jurors’ greater rates of in-group favoritism (Devine \& Caughlin, 2014) and their heightened awareness and sensitivity to bias against Black defendants (Kahn \& Martin, 2020; Weitzer \& Tuch, 2005), Black jurors may place higher importance on race, making them more likely to have an ownrace bias and more resistant to UBJ remedies. Thus, the UBJ video is not expected to 
reduce Black jurors’ expression of racial bias - they will still demonstrate leniency toward the Black defendant.

H3. We expect an interaction between defendant race, juror race, and the UBJ instructions on verdicts, culpability, and credibility. The UBJ instructions will have the greatest impact on the expression of racial bias for White jurors (see H2 above for details/explanation).

H4. Counterfactual endorsement and defendant credibility will mediate the juror race $\mathrm{x}$ defendant race effect on verdicts (described in H1), with lower credibility ratings, lower endorsement of suicide counterfactuals, and higher endorsement of murder counterfactuals resulting in a greater likelihood of a guilty verdict.

\section{Study 1 - Murder Trial}

\section{Method}

The methods for these studies were reviewed and approved by the Institutional Review Board at the PI's university (protocol ID: STUDY001737). The methods for these studies are identical except for the type of trial (murder vs. battery) and resulting semantic differences in the measures. The data, stimuli, and measures from the pilot and current studies are available in the OSF Project: https://osf.io/k5fpa/?view_only=9880bbc7e5fc47b6be7748995d2656b8 .

\section{Participants}

Based on the range of effect sizes in prior studies evaluating the effect of defendant race on jurors' decisions, a small effect size $(f=.15)$ was assumed (see Mitchell et al., 2005, pp. 636637). Using G*Power (Faul et al., 2007) and an $f=.15$, alpha of .05, 90\% power, with 16 groups and a numerator $d f=1$, a sample size of 469 was needed to test main effects and interactions.

Participants were recruited using Qualtrics Panels and compensated \$2.00 for completing 
the survey. Additionally, all participants were 18 years or older, U.S. citizens, and not convicted felons. These criteria are requirements for jury participation in the state where the PI is located. Study 1 included 554 participants (age 18 to 75, $M=46.53$, $S D=17.09$ ): 272 (49.1\%) female; 277 (50.0\%) Black; 277 (50.0\%) White. Data from an additional 170 participants were excluded for failing the attention/manipulation checks (see Measures section for summaries of attention/manipulation checks). Another 14 participants were excluded for finishing the survey in less than half of the median soft-launch time for their condition (i.e., with vs. without video).

\section{Design}

The study employed a 2 (Defendant Race: Black vs. White) x 2 (Mock-Juror Race: Black vs. White) x 2 (UBJ Video: present vs. absent) x 2 (Jury Instructions: UBJ vs. general) betweensubjects design. Cell sizes for the 16 conditions ranged from 34 to 39. Table A (supplemental materials) presents the participant race $\mathrm{x}$ gender breakdown for cells within conditions.

\section{Trial Stimuli}

The murder trial transcript was edited from an actual trial used in past research $-N J v$. Bias (e.g., Hope et al., 2004; Pritchard \& Keenan, 1999, 2002) and is ambiguous toward guilt (Ruva \& McEvoy, 2008). Notably, ambiguous cases are more likely to go to trial while unambiguous cases resolve through plea bargaining (Ingriselli, 2015). The trial was renamed NJ v. Johnson to avoid inadvertently alerting participants to the purpose of this research. The defendant was charged with murdering his wife. The defendant claimed his wife's death was an accident—she threatened to kill herself and the gun went off when he tried to take it from her. During the trial, three prosecution witnesses (police officer who responded to the 911 call, a detective, and the coroner) and two defense witnesses (a mental health counselor and the defendant) testified. Witnesses were subjected to direct and cross-examination. The transcripts 
included photos of the defendant, police officer, detective, medical examiner, defense and prosecuting attorneys, and the judge. Finally, to improve attention, the trial transcripts were broken into three sections and each section was followed by two true/false questions.

\section{Independent Variables}

Defendant Race. Participants were randomly assigned to trials involving a Black or White defendant. To increase stimulus sampling, three photos from the Eberhardt Face Database (Eberhardt et al., 2004) were used for each defendant race condition. These photos were rated moderate in racial stereotypicality, attractiveness, and within the 20-25 year age range. We collapsed across the photo conditions because verdicts did not vary by photo in the pilot study. The pilot study also found that jurors were more likely to find the White (versus Black) defendant guilty (74.5\% vs. 51\%), $\chi^{2} s(1, N=206)=12.24, p<.01, V=.24$.

Unconscious Juror Bias (UBJ) Video. The Western District of Washington (United States District Court, Western District of Washington, 2017) developed the UBJ video (duration $=10: 53$ min.) used in courts today based on the assumption that it reduces jurors' implicit biases. Prior to reading the trial summary participants were randomly assigned to view this video or not. The UBJ video can be found here: https://www.wawd.uscourts.gov/jury/unconscious-bias.

Unconscious Juror Bias (UBJ) Instructions. The Western District of Washington (United States District Court, Western District of Washington, 2017), also developed the UBJ instructions, which are administered pretrial and posttrial. Participants were randomly assigned to read these instructions or the general jury instructions. The general jury instructions do not mention unconscious bias, whereas the UBJ instructions define unconscious bias and explain how it can affect evidence interpretation, credibility perceptions, and decisions. 


\section{Measures}

Exploratory factor analysis (EFA) with Varimax rotation (when more than one factor was indicated) was used for all of the multi-item measures below to determine the number of factors and their structure. Criteria for determining the number of factors included examining the scree plots, the percentage of variance explained by each factor, factor loading of .40 or greater, and content validity of the items loading on the factor. Cronbach's alphas were run to determine internal consistency of each factor. Items were deleted if the Cronbach’s alpha if deleted determined any items were substantially reducing the internal consistency of the scale.

Verdict. Mock jurors provided a dichotomous murder verdict (guilty/not guilty).

Culpability. There were five items for which participants rated the defendant (two items) and victim (two items) on responsibility for the victim's death or injury (1= not at all responsible to 7 = completely responsible), and defendant motive to kill/injure (one item; 1 = strongly agree to 7 = strongly disagree). We expected the culpability items to load on two factors: defendant and victim culpability. Only the defendant culpability scale had good internal consistency (Cronbach's alpha $=0.83$; factor loadings 0.74 to 0.86 ). The scale consisted of three items: (1) How responsible is the defendant for the victim's death? (2) The defendant could have prevented the victim's death, and (3) The defendant had motive to kill the victim.

Defendant Credibility. The defendant credibility scale, used in prior research with good internal consistency (Ruva \& McEvoy, 2008), consisted of 10 items. Nine have seven-point scales (e.g., 1 = not at all credible to 7 = completely credible) and one item is on an 11-point scale (converted to 7-point scale for analyses). All 10 items loaded on a single credibility factor (loadings ranged from .40 to .89), with excellent internal consistency (Cronbach’s alpha $=.90$ ). 
Counterfactual Endorsement. Participants read nine statements about the case, six with counterfactual (“if-then”) implications and three without (e.g., “The defendant loved his wife.”). Participants indicated how strongly they agreed with each statement on a seven-point scale $(1=$ strongly disagree to 7 = strongly agree). EFA with Varimax rotation revealed that four of the counterfactual items loaded on two factors (murder and suicide) with acceptable reliability (Cronbach's alphas $=.71$ and .73). The murder factor consisted of two items (loadings $=.71$ and .81): (1) "If Lisa had not asked for a divorce, she would still be alive today” and (2) "If Daniel had not lost his patience during his argument with Lisa, then Daniel would not have shot Lisa.” The suicide factor consisted of two items (loadings $=0.74$ and 0.75): (1) "If Lisa had gone to regular appointments with a mental health counselor, she would be alive today" and (2) "If Daniel Johnson had taken the previous suicidal threats from his wife more seriously, Lisa Johnson would be alive today.” While convention suggests a three-item minimum per factor, a factor with two items is considered reliable when the items within the factor are highly correlated with each other $(r>.70)$ and comparatively uncorrelated with other items (Yong \& Pearce, 2013).

Manipulation Check Questions. Multiple choice manipulation check questions appeared at the end of the survey. Participants identified the race of the defendant, type of crime charged with, and the defendant's relationship to the victim. Participants were excluded if they incorrectly answered any of these questions.

Attention Check Questions. The trial transcripts were divided into three sections. Each section was followed by two true/false questions (e.g., "Footage from the defendant's interrogation was shown in court” and “A Mental Health Counselor testified in court”). An accuracy rate greater than 50\% was required for inclusion in the data analyses. Participants who 
viewed the UBJ video answered six questions about this video immediately after viewing it.

Incorrectly answering either of the following questions resulted in data exclusion: "Who was the first speaker in the video?” and "What was the main topic of the video?”

\section{Procedure}

Participants were recruited through Qualtrics Panels via an email with the survey link. Data collection took place from 2/5/2021 through 3/23/2021, with most data collected by 3/1/21 (90\%). After providing informed consent, participants completed the demographic questionnaire containing the four inclusion criteria and were randomly assigned to the eight experimental conditions. Prior to reading the trial summary, participants in the UBJ Video condition viewed the video and answered its associated attention checks. All participants were provided with pretrial instructions (general or UBJ), read the trial summary that was divided into three sections and answered two attention checks after each section. Participants were then given trial specific instructions followed by either posttrial general or UBJ instructions. They then rendered verdicts, completed the culpability, credibility and counterfactual scales, and manipulation checks.

\section{Analyses}

To test H1-H3, we performed a series of 2 (Defendant Race: Black vs. White) x 2 (Juror Race: Black vs. White) x 2 (UBJ Video: present vs. absent) x 2 (Jury Instruction: UBJ vs. general) factorial ANOVAs ${ }^{1}$ for the culpability, credibility, and counterfactual endorsements. For the dichotomous verdict, loglinear ANOVA was used and the effect size was Cramer's $V$. For the remaining dependent measures, effect sizes were omega squares for main effects and

\footnotetext{
${ }^{1}$ ANCOVAs for the continuous variables and Logistic Regression for the dichotomous verdicts were run with participant gender entered as a covariate. Adding this covariate did not affect the overall pattern of results for any of the dependent measures. Also, only for the credibility ratings in Study 1was there a significant effect of gender-but the pattern of results did not differ from analyses without the gender covariate. As can be seen in Table A (supplemental materials), gender percentages were similar across conditions. Therefore, analyses without the gender covariate are presented.
} 
interactions, and Cohen's $d$ for the simple effect contrasts. To minimize the likelihood of false effects due to multiple tests, the Benjamini-Hochberg (B-H) procedure was used for all followup tests (Benjamini \& Hochberg, 1995). Process Model 4 (Hayes, 2018) was used to test H4.

\section{Results}

Verdicts

The effect of defendant race on murder verdicts was qualified by a defendant race $\mathrm{x}$ juror race interaction (see Tables 1 and 2). Contrary to H1, White jurors were more likely to find the White defendant guilty than the Black defendant. Additionally, only when the defendant was Black did Black and White jurors differ in their verdicts-White jurors were less likely to render a guilty verdict than Black jurors (see Tables 1 and 2). Contrary to $\mathrm{H} 2$ and H3, the UBJ video and instructions did not affect murder verdicts.

\section{Defendant Culpability and Credibility}

Consistent with murder verdicts, defendant race had a significant effect on jurors’ ratings of defendant culpability and credibility, which was qualified by a defendant race $\mathrm{x}$ juror race interaction (see Tables 1 and 3). Once again, contrary to H1, the interaction was due to defendant race only affecting White jurors. Specifically, White jurors rated the White defendant higher in culpability and lower in credibility than the Black defendant. Additionally, only when the defendant was Black did Black and White jurors differ in their culpability ratings. White jurors rated the Black defendant lower in culpability than Black jurors - this was not true for the credibility ratings (see Tables 1 and 3). Contrary to $\mathrm{H} 2$ and H3, the UBJ video and instructions did not affect defendant culpability or credibility.

\section{Counterfactual Endorsement (Exploratory Analyses)}


Only juror race was associated with the endorsement of the suicide counterfactuals, with Black jurors having higher endorsement than White jurors (see Table 1), $F(1,538)=28.19, M S E$ $=10.84, p<.001, \omega^{2}=.05,95 \%$ CI $[.02, .09]$. Endorsement of the murder counterfactuals was affected by defendant race and jury instructions, $F s(1,538)=4.82$ and $8.09, M S E=11.99$, $p s=$ .03 and $.005, \omega^{2}=.01$ and $.015,95 \%$ CI $[.00, .03]$ and $[.001, .04]$. There was greater endorsement of the murder counterfactuals (points toward defendant guilt) when the defendant was White, as opposed to Black (see Table 1), and when the UBJ instructions were present, as opposed to absent ( $M s=8.71$ and 7.89, $S D s=3.45$ and 3.51, respectively).

While the defendant race $\mathrm{x}$ video interaction did not meet conventional standards of significance for the murder counterfactuals, we probed the interaction given its relevance to our research questions (i.e., efficacy of the UBJ video), $F(1,545)=3.40, M S E=11.99, p=.066, \omega^{2}$ $=.01,95 \%$ CI $[.00, .03]$. When the video was absent, jurors’ endorsement of murder counterfactuals was higher for the White defendant than the Black defendant $(M s=8.93$ and 7.77, $S D s=3.28$ and 3.74, respectively), $t(1,284)=2.90, p=.004, d=-.33$, 95\% CI [-.56, -.11]. When the video was present, defendant race did not affect endorsement of murder counterfactuals ( $M s=8.34$ and 8.23, $S D s=3.39$ and 3.49, respectively), $t(1,545)=-.25, p=.85$.

\section{Mediation Analyses (H4)}

Given that only White jurors were affected by the defendant's race in terms of verdicts and defendant credibility ratings, we examined multiple mediational effects separately for Black and White jurors using Process Model 4, with 5,000 bias corrected bootstrap samples (Hayes, 2018; see Figure 1). Defendant and juror race was dummy coded so that $0=$ White and $1=$ Black. Replicating our previous findings, Black jurors’ verdicts, defendant credibility ratings, 
and counterfactual endorsement were not affected by defendant race. Therefore, only the mediation analyses for the White jurors are presented below.

Consistent with the findings above, defendant race had a direct effect on White jurors’ ratings of defendant credibility and their endorsement of murder counterfactuals. Also, guilty verdict decisions were negatively associated with defendant credibility and positively associated with murder counterfactual endorsement. These variables mediated the effect of defendant race on verdicts (see Figure 1). Specifically, White jurors rated the Black defendant higher in credibility and indicated lower endorsement of murder counterfactuals compared to the White defendant, which in turn increased the likelihood of finding the Black defendant not guilty.

\section{Discussion}

Study 1 evaluated the impact of defendant race, juror race, and two unconscious bias remedies (video and instructions) on jurors' decisions regarding guilt, credibility, culpability, and counterfactual endorsement in a murder trial in which a husband is accused of killing his wife. Contrary to our predictions (H2 and H3), the UBJ video and instructions did not affect verdicts. Also contrary to our predictions (H1), the results demonstrate an overcorrection of bias in White jurors. While White and Black jurors did not differ in their verdicts for the White defendant, White jurors found the Black defendant guilty less often than Black jurors. Defendant credibility and culpability ratings followed a similar pattern, with White jurors’ culpability ratings of Black defendants suggestive of overcorrection. These findings deviate from past research suggesting that jurors of the same race as the defendant will act more leniently (Mazzella \& Feingold, 1995; Mitchell et al, 2005). Nevertheless, these results are consistent with recent research in which White jurors showed favoritism toward Black defendants as opposed to White defendants (Clow et al., 2013; Petsko \& Bodenhausen, 2019; Peter-Hagene, 2019) and rated Black defendants (vs. 
White defendants) more capable of rehabilitation (Hughes et al., 2021). While the results may seem consistent with the black sheep effect, this is unlikely since White jurors did not treat White defendants harsher, but rather treated Black defendants more leniently. Further, the black sheep effect occurs when the evidence is clear but Study 1's trial stimuli was ambiguous toward guilt. An alternative explanation for these findings lies in the flexible correction model. This model asserts that attempts at bias correction do not always result in remediation of the bias and can result in overcorrection. It is possible that recent racially charged events (e.g., the murder of George Floyd) created a desire for White jurors to appear antiracist and motivated them to correct bias (Hughes et al., 2021), but without proper awareness of the extent of their bias they overcorrected (Wegener \& Petty, 1997). An additional explanation for these findings could be attributed to the type of crime used in Study 1. Although there is not an established race crime congruency for defendant race and IPV, there are important racial distinctions depicted in the media. While Black male perpetrators of IPV are represented more negatively (Pepin, 2016), there is a higher prevalence of White male perpetrators of IPV in the news overall (Sellers et al., 2014). Thus, jurors may have held a greater association with IPV and White male perpetrators, and consequently found the White defendant guilty more often.

Endorsement of murder counterfactuals was affected by defendant race and UBJ instructions_-endorsement increased when the defendant was White, as well as when UBJ instructions were present. Additionally, when the video was present, defendant race did not affect jurors' endorsement. Though the UBJ video and instructions did not impact verdicts, their impact on counterfactual endorsement indicates that both deserve further research in other contexts (e.g., civil trials). This last point is supported by the finding that counterfactual endorsement, along with defendant credibility, mediated the effect of defendant race on White 
jurors’ murder verdicts. This could be a combination of overcorrection for bias (through defendant credibility) and jurors’ endorsement of murder counterfactuals. The impact of the UBJ video on murder counterfactuals indicates that a revised version of voir dire that engages jurors in actively combatting implicit bias may be able to decrease racial bias in jurors (Lai et al., 2014), which we explore in the Future Directions section. The impact of the UBJ video and instructions are further explored in Study 2, which examined the same variables in the context of a less severe crime that is stereotypically congruent with Black defendants.

\section{Study 2 - Battery Trial}

\section{Method}

\section{Participants, Design, and Procedure}

Study 2 included 539 participants recruited from Qualtrics Panels (age 18 to 75, $M=$ 46.46, SD = 16.00): 272 (50.5\%) female; 267 (49.5\%) Black; 272 (50.5\%) White. An additional 260 participants were excluded due to failing one or more of the attention/manipulation checks. Another 16 participants were excluded for completing the survey in less than half of the median soft-launch time for their condition (i.e., with and without the UBJ video).

Study 2 employed the same design as Study 1. Cell sizes for the 16 conditions ranged from 31 to 36 (see supplemental materials Table A for participant race x gender breakdown of conditions). The procedure for Study 2 was identical to that of Study 1.

\section{Trial Stimuli}

The battery trial (State v. Rollins) was an edited version of a trial stimulus used by Elek and Agor (2014). A study using a briefer version of this case summary found that the defendant's race influenced judges’ verdict decisions (Rachlinski et al., 2009). In the current study, the trial stimulus was lengthened to increase ecological validity-including more about the charges and 
prosecution and defense cases. The defendant (starting quarterback) was charged with battery resulting in serious bodily injury of a teammate and known rival. In an altercation between the defendant and victim, the defendant threw the victim off himself, causing the victim to collide with an eyewitness and fall over a bench. As a result, the victim tore his anterior cruciate ligament (ACL), suffering permanent loss of mobility in his leg. The defendant claimed he was acting in self-defense and the injury was accidental. Jurors were instructed on the relevant law for the charge. The trial summary included photos of the defendant (race manipulation), the judge, and prosecuting attorney, as well as an image of the ACL injury. Finally, to improve attention, the trial summary was broken into two sections. Each section was followed by two true/false questions.

A pilot study found the trial summary to be ambiguous towards guilt. It also found that the White (versus Black) defendant was more likely to be found guilty (56.3\% vs. $41.2 \%), \chi^{2}(1$, $N=206)=4.54, p=.03, V=.15$.

\section{Independent Variables}

Study 2 manipulated the same variables in the same manner as Study 1 (i.e., defendant race, UBJ video, and UBJ instructions).

\section{Measures}

EFA was again performed for all of the multi-item measures below.

Verdict. Mock jurors provided dichotomous verdicts (guilty/not guilty) for the Battery with Serious Bodily Injury charge.

Culpability. Culpability items were the same as those used in Study 1 except the crime (murder vs. battery) and outcome (death vs. injury) differed. These items were expected to load 
on two factors: defendant and victim culpability. Only the defendant culpability scale had good internal consistency (Cronbach’s alpha $=.72$ ).

Defendant Credibility. The same 10 items as Study 1 loaded on a single factor (loadings ranged from .40 to .89 ), with excellent internal consistency (Cronbach’s alpha $=.88$ ).

Counterfactual Endorsement. Participants responded to eight statements about the case, five having counterfactual implications and three that did not (e.g., The victim's injuries were an unfortunate accident). Participants indicated how strongly they agreed with each statement on a seven-point scale $(1=$ strongly disagree to 7 = strongly agree). EFA revealed two factors: victim factor consisting of three items and defendant factor consisting of two items. However, internal consistency was low for both factors (Cronbach’s alphas = .55 and .56, respectively). Therefore, these items were excluded from further analyses because assessing counterfactual endorsement of a single item would be misleading at best and invalid at worse.

Manipulation and Attention Questions. Study 2 employed the same manipulation check questions and similar attention check questions as Study 1.

\section{Results}

Verdicts

Black jurors were more likely to find the defendant guilty than White jurors, $\chi^{2}(1,554)=$ 4.13, $V=.09, p=.04$ (see Table 2). Contrary to H1-H3, there were no other main or interaction effects for verdicts.

\section{Defendant Culpability and Credibility}

Contrary to H1-H3, there were no main or interaction effects of the independent variables on defendant culpability, $F s(1,523)<1.86$, ps $>.16$. 
There was a main effect of video on jurors’ ratings of defendant credibility, which was qualified by a video x jury instruction interaction (see Table 4). The defendant was rated as more credible when UBJ video was present versus absent (see Table 5). The interaction was due to there being no effect of the UBJ video on credibility ratings when UBJ instructions are present (see Tables 4 and 5). In contrast, when general instructions were provided (that is, UBJ instructions were absent), jurors exposed to the UBJ video rated the defendant more credible than those not exposed to the video. Notably, jurors' ratings of defendant credibility were lowest when neither the UBJ video nor UBJ instructions were present, and differed from the condition having both remedies present.

Although the juror race $\mathrm{x}$ video interaction did not meet conventional levels of significance (see Table 4), we probed the interaction due to its importance to our research questions (efficacy of UBJ video in reducing bias). When the video was present, Black jurors rated the defendant higher in credibility than when it was absent $(M s=49.30$ and $44.70, S D s=$ 11.61 and 14.09, respectively). The video did not affect White jurors’ credibility ratings (Ms = 48.64 and 47.86, SDs = 12.03 and 12.41, respectively). Additionally, only when Black jurors did not view the video did their credibility ratings differ from the White jurors’ ratings (see Table 4).

\section{Mediation Analyses (H4)}

Given that defendant race and the defendant race $\mathrm{x}$ juror race interaction did not affect verdicts, the mediation model tested was Process Model 4 (Hayes, 2018): (X) juror race $\rightarrow$ (M) defendant credibility $\rightarrow$ (Y) verdict. The indirect effect of credibility on verdict was not significant $[a b=0.14,95 \%$ CI $(-0.11,0.41)]$. Therefore, jurors’ defendant credibility ratings did not mediate the effect of juror race on verdicts.

\section{Study 2 Discussion}


Study 2 examined the impact of defendant race, juror race, and two unconscious bias remedies on jurors' decisions regarding guilt, credibility, and culpability in a battery trial in which a university quarterback was charged with battery resulting in serious bodily injury of a teammate. White jurors were more likely than Black jurors to find the defendant not guiltysuggesting that regardless of defendant race, White jurors were more lenient. Importantly, this finding is counter to prior research finding Black jurors more lenient than White jurors (Fitzgerald \& Ellsworth, 1984; Foley \& Chamblin, 1982; Shaw et al., 2021; Sommers \& Ellsworth, 2000). However, in the context of the OJ Simpson trial, White jurors viewed defendants of an elevated status (celebrity/athlete) more favorably than Black jurors (Skolnick \& Shaw, 1997). Thus, the elevated status of the defendant in Study 2 (i.e., university starting quarterback) may partially explain White jurors’ leniency (or Black jurors punitiveness), a bias that the UBJ remedies were designed to address.

Consistent with Study 1's findings neither the UBJ instructions nor video influenced verdict decisions. The UBJ interventions were meant to address juror bias associated with characteristics of the trial participants (e.g., the defendant, witnesses, attorneys), including the status of the defendant, and thus had the opportunity to remediate such bias in this study. Also consistent with Study 1, the UBJ video influenced a variable that has been shown to mediate juror verdicts (i.e., credibility). Specifically, when the UBJ video was present, Black jurors rated the defendant higher in credibility than when it was absent. Additionally, when the video was present, the Black and White jurors no longer differed in their credibility ratings, suggesting a bias correction for Black jurors — similar to the correction found for White jurors’ murder counterfactual endorsements in Study 1. 


\section{General Discussion}

The present studies examined the impact of defendant race, juror race, and two UBJ remedies (video and instructions) on a range of juror decisions (i.e., verdicts, ratings of culpability and credibility, and counterfactual endorsements). Across both studies we found no main or interaction effect of UBJ remedy (video or instructions) on verdicts. However, there were effects of the UBJ video and/or instructions on murder counterfactuals in Study 1 (murder trial), as well as defendant credibility in Study 2 (battery trial). The relationship between juror and defendant race with verdict decisions varied considerably between the two studies, with White jurors treating the Black defendant more leniently in Study 1, and White jurors treating all defendants more leniently in Study 2.

\section{Unconscious Bias Remedies}

Importantly, juror race predicted or moderated verdicts across both studies which allowed exploration of the effectiveness of the UBJ interventions in reducing bias in verdicts. Neither UBJ remedy reduced bias in verdicts. They did, however, show promise for positively influencing certain aspects of juror bias (i.e., counterfactual endorsement and defendant credibility) that have mediational effects on verdict decisions (Alvarez \& Miller, 2016; Ruva \& McEvoy, 2008). Specifically, in Study 1 the UBJ video decreased White jurors' endorsement of murder counterfactuals, but did not affect Black jurors' endorsements. When the video was present, defendant race no longer affected the endorsement of murder counterfactuals. Further, the endorsement of murder counterfactuals mediated the effect of defendant race on White jurors' verdicts, indicating that counterfactual endorsement along with defendant credibility are key components in guilt decisions. In Study 2, the UBJ video increased Black jurors’ credibility 
ratings, but had no effect on White jurors’ ratings. Only when the video was absent did Black and White jurors differ in their credibility ratings, with Black jurors providing lower ratings.

Although the UBJ interventions reduced certain aspects of juror bias, they also showed cause for concern. In Study 1 when UBJ instructions were present, mock jurors more strongly endorsed the murder counterfactuals (and rated the defendant more culpable) and, in turn, were more likely to render a guilty verdict. The UBJ instructions’ effect on counterfactual endorsement (and culpability ratings) indicates that they could have unintended consequences on jurors' decisions that result in a greater likelihood of a guilty verdict. This effect could be due to direct language in the instructions (e.g., "You must avoid bias, conscious or unconscious”) that may incite defensive responding or backlash in jurors. To be effective, implicit bias interventions must decrease blameworthiness and increase jurors’ perception that bias can be controlled (Vitriol \& Moskowitz, 2021). Further research is needed to confirm the replicability of these effects and to evaluate the UBJ remedies in other contexts (e.g., a civil trial or different crime types). Despite the differences in the trial stimuli used (murder vs. battery), the UBJ remedies were ineffective at reducing bias in juror verdicts across both studies.

\section{Racial Bias in Jurors}

Though the efficacy of the UBJ remedies was our main focus, this research sheds light on juror racial bias. Juror race moderated the effect of defendant race on verdicts, but only in Study 1. The direction of this moderating effect was contrary to what we predicted. White jurors were more likely to convict White but not Black defendants. Yet, White jurors were not more punitive toward the White defendant than Black jurors; rather, they were more lenient towards the Black defendant. These findings are consistent with recent research that has found a pattern of White 
jurors behaving more leniently toward minority defendants (Clow et al., 2013; Hughes et al., 2021; Peter-Hagene, 2019; Petsko \& Bodenhausen, 2019).

Aversive racism theory is useful in explaining these findings as it asserts that White jurors will attempt to align decisions with their egalitarian views when race is salient (Dovidio et al., 1998; Dovidio \& Gaertner, 2004). As the recent highly publicized trial of Derek Chauvin demonstrates, White jurors are unlikely to exhibit racial bias when race is salient (Hughes et al., 2021; Ingriselli, 2015; Sommers \& Ellsworth, 2000, 2001). Similarly, systemic injustices that disproportionately impact Black Americans, including higher arrest rates and longer sentences, have been highlighted recently and may contribute to chronic racial salience in juror decision making (Hetey \& Eberhardt, 2014). Study 1 detailed a more severe offense (murder) than Study 2 (battery), which may have triggered greater race salience, encouraging White jurors to correct their bias to align with their egalitarian views. However, jurors were not aware of the extent of their bias and so overcompensated (Wegener \& Petty, 1997). Alternately, following the murder of George Floyd, White jurors may desire to appear antiracist (Hughes et al., 2021).

Study 2 revealed that juror race predicted verdict. White jurors were more lenient toward defendants of both races compared to Black jurors. This is inconsistent with previous research finding Black jurors more lenient than White jurors (Fitzgerald \& Ellsworth, 1984; Foley \& Chamblin, 1982; Shaw et al., 2021; Sommers \& Ellsworth, 2000). Interestingly, in the context of the OJ Simpson trial, mock jurors viewed high-status defendants more favorably than low-status defendants. Notably, White jurors viewed elevated status (celebrity/athlete) more positively than Black jurors in their personal evaluations of a defendant (Skolnick \& Shaw, 1997). The battery case used in Study 2 depicted a defendant that is a starting quarterback for a university, thus giving Study 2’s defendant an elevated status. 
Additional differences in the trial stimuli may partially explain the varied effects of defendant and juror race on verdicts across the two studies. Study 1 concerned a crime perpetrated by a man against a woman, whereas in Study 2 both the defendant and victim were men. This raises questions of gender stereotypes and how they may interact with racial stereotypes in different situations. Future research should vary the gender of defendants and victims to examine the role gender plays in juror bias, especially in cases of domestic violence. Further, different ages of the defendant may have been presumed across the two studies (college students vs. married couple). These characteristics, defendant status and age, as well as victim gender, are individual differences that the UBJ remedies were designed to address. In fact, an example of gender discrimination is highlighted in the UBJ video. Despite such differences, the bottom line remains that the UBJ video and instructions were not effective at reducing bias in mock-juror verdicts in either trial, but did reduce juror bias in variables associated with verdict decisions (i.e., counterfactual endorsement and credibility).

Overall, our findings reflect a shift in racial bias in juror decision making which is consistent with more current research (Hughes et al, 2021; Peter-Hagene, 2019; Petsko \& Bodenhausen, 2019). White jurors generally behave more leniently toward minority defendants presumably to appear less prejudicial. Bias against Black Americans certainly still exists and is becoming more widely recognized. This recognition is likely accompanied with greater pressure for White jurors to appear nonbiased and consequently overcorrect in the process.

\section{Limitations}

Given that the current study used typical juror simulation procedures, there are some common limitations. Namely, the use of a trial transcript and trial summary, both of which are shortened for practical reasons, and do not mimic the amount of information jurors receive at 
trial. The public format associated with real-life trials may elicit less honest responses (Krysan, 1998), which may intensify overcorrection in White jurors who feel pressure to conform to societal norms/egalitarian beliefs. Additionally, this study was done on individual jurors without deliberation. Given that racial diversity on juries decreases racial bias (Sommers, 2006) and increases the quality of deliberation and decision making (Bergold \& Kovera, 2020), deliberating in diverse groups may result in less biased outcomes. Timing of data collection is also important to note. Given the public events over the past few years, race was likely highly salient in participants' minds. Trials taking place during this time and in the foreseeable future are likely to be in a similar atmosphere where race continues to be salient and vulnerable to bias. Additionally, the current study explored differences only within the context of Black and White individuals. Thus, our findings cannot be extended to other groups such as Asian or Hispanic/Latino/a jurors.

Finally, we acknowledge that data quality may have also been hindered by the number of excluded participants based on failed attention and manipulation checks (AMCs) and the source of the sample. Loss of data due to failed AMCs is not uncommon in this field and others (Abbey \& Meloy, 2017; Cullen \& Monds, 2020; Ruva \& Sykes, 2022; Salerno et al., 2021). Scholars have debated the use of AMCs, with some evidence suggesting they improve data quality (Abbey \& Meloy, 2017; Shamon \& Berning 2020) and others suggesting the opposite (Anduiza \& Galais, 2017; Aronow et al., 2019). Another issue for data quality may be the source of the sample. Recent evidence suggests that the rate of AMC failures is higher with Qualtrics Panels compared to other online participant recruitment platforms, such as mTurk and Prolific (Peer et al., 2021). However, this study also noted that Qualtrics participants who successfully passed AMCs better understood the experimental instructions and outperformed samples recruited via 
mTurk. Clearly, more research on data quality related to both the use of AMCs and different participant recruitment platforms is needed.

\section{Future Directions}

The current research contributes to a growing body of literature involving implicit racial bias in juror decision making. It is the first research, that we are aware of, to explore the efficacy of the UBJ video and instructions. Thus, further research is needed to draw broader conclusions regarding their effectiveness. That said, we propose evidence-based suggestions to improve these interventions. Currently, a significant portion of the UBJ video is allotted to self-identification/ awareness of a juror's unconscious bias, however individuals are not well adept at identifying their own biases (bias blind spot) and such awareness does not translate into avoiding bias (West et al., 2012). A greater focus on enabling jurors to take a more active role could more effectively combat implicit biases (Devine et al., 2012), whether that comes from real-time feedback (Morewedge et al., 2015) or perspective taking (Salmanowitz, 2018). The UBJ video stops short of explicitly asking jurors to take the perspective of an individual adversely affected by unconscious bias; however, it is a strategy that could be used in the video format. Other options to improve racial bias interventions include encouraging specific counterfactual thinking by providing jurors with prompts that mitigate bias (e.g., If the Black defendant was White, would you make the same decision?) and case-specific approaches to bias reduction (Calanchini et al., 2020) rather than a universal method that the current UBJ video utilizes.

Additionally, more research is needed to find an effective and practical way to provide jurors with real-time feedback on bias. While there may be practical limitations for implementation in voir dire, a combination of the UBJ video with an Implicit Association Test (IAT) may provide jurors with feedback on the direction and extent of their bias. Although the 
validity of the IAT has been called into question (e.g., Schimmack, 2021), it is one of the best tools currently available to assess automatic cognitions on an individual level (Vianello \& BarAnan, 2021; Kurdi et al., 2021). However, IAT feedback may result in defensive responding (Howell \& Ratliff, 2017). Any feedback given should be paired with an intervention that decreases blameworthiness (e.g., indicate that everyone holds biases) and increases the perception that biases are controllable (Vitriol \& Moskowitz, 2021).

\section{Conclusion}

In summary, the debiasing interventions (UBJ video and instructions) in their current form are not effective in reducing racial bias in jurors' verdict decisions. However, they do impact aspects of jurors’ legal judgments and may be more effective in a modified form. Additionally, the presence of two interventions did not decrease bias beyond the presence of a single remedy for juror decisions, indicating that in their current form the UBJ video should be used alone until further research investigates the direction/effect of the accompanying instructions. The effect and direction of racial bias found in this research indicates the need for persistent scrutiny as bias continues to evolve with changing times. Understanding how jurors are affected by racial tension and events in society and thus what remedies may be most effective in combatting them are an important step in guaranteeing every defendant’s right to a fair trial.

\section{Data Availability Statement}

The data that support the findings of this study are openly available in OSF at https://osf.io/k5fpa/?view_only=9880bbc7e5fc47b6be7748995d2656b8. Project titled “The effectiveness of Two Unconscious Bias Remedies for Reducing Bias in Juror Decision Making. 


\section{References}

Abbey, J. D., \& Meloy, M. G. (2017). Attention by design: Using attention checks to detect inattentive respondents and improve data quality. Journal of Operations Management, 53, 63-70. https://doi.org/10.1016/j.jom.2017.06.001

Abrams, D., \& Hogg, M. A. (2004). Metatheory: Lessons from social identity research. Personality \& Social Psychology Review (Lawrence Erlbaum Associates), 8(2), 98-106. https://doi.org/10.1207\%2Fs15327957pspr0802_2

Alvarez, M. J., \& Miller, M. K. (2016). Counterfactual thinking about crime control theater: Mock jurors’ decision making in an AMBER Alert trial. Psychology, Public Policy, and Law, 22(4), 349-361. http://dx.doi.org.ezproxy.lib.usf.edu/10.1037/law0000098

Anduiza, E., \& Galais, C. (2017). Answering without reading: IMCs and strong satisficing in online surveys. International Journal of Public Opinion Research, 29(3), 497-519. https://doi.org/10.1093/ijpor/edw007

Aronow, P. M., Baron, J., \& Pinson, L. (2019). A note on dropping experimental subjects who fail a manipulation check. Political Analysis, 27(4), 572-589. https://doi.org/10.1017/pan.2019.5

Batson v. Kentucky, 476 U.S. 79 (1986)

Benjamini, Y., \& Hochberg, Y. (1995). Controlling the false discovery rate: A practical and powerful approach to multiple testing. Journal of the Royal Statistical Society, 57(1), 289-300. https://doi.org/10.1111/j.2517-6161.1995.tb02031.x

Bergold, A. N., \& Kovera., M. B. (2020). The effects of racial bias and jury diversity on juror decision making. In J. Cooper and J. Avery (Eds.), Bias in the law: A definitive look at racial prejudice in the U.S. criminal justice system (pp. 115-140). Lexington Books. 
Calanchini, J., Lai, C. K., \& Klauer, K. C. (2021). Reducing implicit racial preferences: III. A process-level examination of changes in implicit preferences. Journal of Personality and Social Psychology, 121(4), 796-818. https://doi.org/10.1037/pspi0000339

CBS. (2021, April 19). Closing arguments presented in Derek Chauvin trial [Video]. YouTube. https://www.youtube.com/watch?v=kw6wiBk0WdU

Clow, K. A., Lant, J. M., \& Cutler, B. L. (2013). Perceptions of defendant culpability in pretrial publicity: The effects of defendant ethnicity and participant gender. Race and Social Problems, 5(4), 250-261. https://doi.org/10.1007/s12552-013-9102-1

Cramer, E. (1999). Variables that predict verdicts in domestic violence cases. Journal of Interpersonal Violence, 14, 1137-1150. https://doi.org/10.1177/088626099014011002

Cullen, H. J., \& Monds, L. A. (2020). Jury simulation studies: To exclude or not to exclude participants based on a lack of comprehension of the case?. Applied Cognitive Psychology, 34(5), 1224-1233. https://doi.org/10.1002/acp.3695

Devine, D. J., \& Caughlin, D. E. (2014). Do they matter? A meta-analytic investigation of individual characteristics and guilt judgments. Psychology, Public Policy, and Law, 20(2), 109-134. https://doi.org/10.1037/law0000006

Devine, P. G., Forscher, P. S., Austin, A. J., \& Cox, W. T. (2012). Long-term reduction in implicit race bias: A prejudice habit-breaking intervention. Journal of Experimental Social Psychology, 48(6), 1267-1278. https://doi.org/10.1016/j.jesp.2012.06.003

Dovidio, J. F., \& Gaertner, S. L. (2004). Aversive racism. In Zanna, M. P. (Ed.), Advances in experimental social psychology (Vol. 36, pp. 1-52). Elsevier Academic Press. https://doi.org/10.1016/S0065-2601(04)36001-6 
Dovidio, J. F., Gaertner, S. L., \& Validzic, A. (1998). Intergroup bias: Status, differentiation, and a common in-group identity. Journal of Personality and Social Psychology, 75(1), 109120. https://doi.org/10.1037/0022-3514.75.1.109

Dovidio, J. F., Ten Vergert, M., Stewart, T. L., Gaertner, S.L., Johnson, J. D., Esses, V. M., Riek, B.M., \& Pearson, A.R. (2004). Perspective and prejudice: Antecedents and mediating mechanisms. Personality and Social Psychology Bulletin, 30(12), 1537-1549. https://doi.org/10.1177/0146167204271177

Eberhardt, J. L., Goff, P. A., Purdie, V. J., \& Davies, P. G. (2004). Seeing black: race, crime, and visual processing. Journal of Personality and Social Psychology, 87(6), 876-893. https://doi.org/10.1037/0022-3514.87.6.876

Elek, J., \& Agor, P. H. (2014). Can explicit instructions reduce expressions of implicit bias? New questions following a test of a specialized jury instruction. National Center for State Courts. http://dx.doi.org/10.2139/ssrn.2430438

Esqueda, C. W., Espinoza, R. K. E., \& Culhane, S. E. (2008). The effects of ethnicity, SES, and crime status on juror decision making: A cross-cultural examination of European American and Mexican American mock jurors. Hispanic Journal of Behavioral Sciences, 30(2), 181-199. https://doi.org/10.1177/0739986308315319

Faul, F., Erdfelder, E., Lang, A.G. \& Buchner, A. (2007). G*Power 3: A flexible statistical power analysis program for the social, behavioral, and biomedical sciences. Behavior Research Methods, 39(2), 175-191. https://doi.org/10.3758/bf03193146

Fitzgerald, R., \& Ellsworth, P. C. (1984). Due process vs. crime control: Death qualification and jury attitudes. Law and Human Behavior, 8(1-2), 31-51.

https://doi.org/10.1007/BF01044350 
Flowers v. Mississippi, 588 U.S. (2019).

Foley, L. A., \& Chamblin, M. H. (1982). The effect of race and personality on mock jurors' decisions. The Journal of Psychology: Interdisciplinary and Applied, 112(1), 47-51. https://doi.org/10.1080/00223980.1982.9923533

Gayla, M. (2017, June 21). A federal court asks jurors to confront their hidden biases [Online]. The Marshall Project. https://www.themarshallproject.org/2017/06/21/a-federal-courtasks-jurors-to-confront-their-hidden-biases

Gordon, R. A., \& Anderson, K. S. (1995). Perceptions of race-stereotypic and racenonstereotypic crimes: The impact of response-time instructions on attributions and judgments. Basic and Applied Social Psychology, 16(4), 455-470. https://doi.org/10.1207/s15324834basp1604_4

Hayes, A. F. (2018). Introduction to mediation, moderation, and conditional process analysis (2nd Ed.). Guilford publications.

Hetey, R. C., \& Eberhardt, J. L. (2014). Racial Disparities in Incarceration Increase Acceptance of Punitive Policies. Psychological Science, 25(10), 1949-1954. https://doi.org/10.1177/0956797614540307

Hope, L., Memon, A., \& McGeorge, P. (2004). Understanding pretrial publicity: Predecisional distortion of evidence by mock jurors. Journal of Experimental Psychology: Applied, 10(2), 111-119. https://doi.org/10.1037/1076-898X.10.2.111

Howell, J., \& Ratliff, K. A. (2017). Not your average bigot: The better-than-average effect and defensive responding to Implicit Association Test feedback. British Journal of Social Psychology, 56(1), 125-145. https://doi.org/10.1111/bjso.12168 
Hughes, J. S., Sandel, A., Yelderman, L. A., \& Inman, V. (2021). Beliefs about an Offender’s Capacity to Be Rehabilitated: Black Offenders Are Seen as More Capable of Change. Basic and Applied Social Psychology, 43(6), 406-422. https://doi.org/10.1080/01973533.2021.1982714

Ingriselli, E. (2015). Mitigating Jurors’ Racial Biases: The Effects of Content and Timing of Jury Instructions. Yale Law Journal, 124(5), 1690-1745.

Innocence Staff. (2018). Judge denies request to show implicit bias video to prospective jurors [Online]. The Innocence Project. https://www.innocenceproject.org/judge-denies-requestto-show-implicit-bias-video/

Jones, C. S., \& Kaplan, M. F. (2003). The effects of racially stereotypical crimes on juror decision-making and information-processing strategies. Basic and Applied Social Psychology, 25(1), 1-13. https://doi.org/10.1207/S15324834BASP2501_1

Kahn, K. B., \& Martin, K. D. (2020). The Social Psychology of Racially Biased Policing: Evidence-Based Policy Responses. Policy Insights from the Behavioral and Brain Sciences, 7(2), 107-114. https://doi.org/10.1177/2372732220943639

Kahneman, D., \& Miller, D. T. (1986). Norm theory: Comparing reality to its alternatives. Psychological Review, 93(2), 136 -153. https://doi.org/10.1037/0033295X.93.2.136

Kang, J., Bennett, M., Carbado, D., Casey, P., Dasgupta, N., Faigman, D. L., Godsil, R., Greenwald, A. G., Levinson, J. D., \& Mnookin, J. (2012). Implicit bias in the courtroom. UCLA Law Review, 59(5), 1124-1186. https://ssrn.com/abstract=2026540

Krysan, M. (1998). Privacy and the expression of White racial attitudes: A comparison across 
three contexts. Public Opinion Quarterly, 62(4), 506-544.

https://doi.org/10.1086/297859

Kurdi, B., Ratliff, K. A., \& Cunningham, W. A. (2021). Can the implicit association test serve as a valid measure of automatic cognition? A response to Schimmack (2021). Perspectives on Psychological Science, 16(2), 422-434. https://doi.org/10.1177/1745691620904080

Lai, C. K., Marini, M., Lehr, S. A., Cerruti, C., Shin, J. E. L., Joy-Gaba, J.A.,...Nosek, B. A. (2014). Reducing implicit racial preferences: A comparative investigation of 17 interventions. Journal of Experimental Psychology: General, 143(4), 1765-1785. http://dx.doi.org/10.1037/a0036260

Lapinski, M. K., \& Mastro, D. E. (2001). A social identity approach to understanding the jury decision-making process: Race as a social indicator. Journal of Intergroup Relations, 28(2), 48-62.

Lieberman, J. D., \& Arndt, J. (2000). Understanding the limits of limiting instructions: Social psychological explanations for the failures of instructions to disregard pretrial publicity and other inadmissible evidence. Psychology, Public Policy, and Law, 6(3), 677-711. https://doi.org/10.1037/1076-8971.6.3.677

Lynch, M., Kidd, T., \& Shaw, E. (2022). The subtle effects of implicit bias instructions. Law \& Policy, 44(1), 98-124. https://doi.org/10.1111/lapo.12181

Mazzella, R., \& Feingold, A. (1994). The effects of physical attractiveness, race, socioeconomic status, and gender of defendants and victims on judgments of mock jurors: A metaanalysis. Journal of Applied Social Psychology, 24(15), 1315-1338. https://doi.org/10.1111/j.1559-1816.1994.tb01552.x 
Melilli, K. J. (1996). Batson in practice: What we have learned about Batson and peremptory challenges. Notre Dame Law Review., 71, 447-503.

https://scholarship.law.nd.edu/ndlr/vol71/iss3/3

Mitchell, T.L., Haw, R.M., Pfeifer JE, Meissner, C.A. (2005). Racial bias in mock juror decision-making: a meta-analytic review of defendant treatment. Law and Human Behavior, 29(6), 621-637. https://doi.org/10.1007/s10979-005-8122-9

Morewedge, C. K., Yoon, H., Scopelliti, I., Symborski, C. W., Korris, J. H., \& Kassam, K. S. (2015). Debiasing decisions: Improved decision making with a single training intervention. Policy Insights from the Behavioral and Brain Sciences, 2(1), 129-140. https://doi.org/10.1177/2372732215600886

O'Brien, B., \& Grosso, C. M. (2020). Criminal Trials and Reforms Intended to Reduce the Impact of Race: A Review. Annual Review of Law and Social Science, 16(1), 117-130. https://doi.org/10.1146/annurev-lawsocsci-042020-111040

Peer, E., Rothschild, D., Gordon, A., Evernden, Z., \& Damer, E. (2022). Data quality of platforms and panels for online behavioral research. Behavior Research Methods, 54(4), 1643-1662. https://doi.org/10.3758/s13428-021-01694-3

Pepin, J. R. (2016). Nobody’s business? White male privilege in media coverage of intimate partner violence. Sociological Spectrum, 36(3), 123-141. https://doi.org/10.1080/02732173.2015.1108886

Peter-Hagene, L. (2019). Jurors’ cognitive depletion and performance during jury deliberation as a function of jury diversity and defendant race. Law and Human Behavior, 43(3), 232249. https://doi.org/10.1037/lhb0000332 
Petsko, C. D., \& Bodenhausen, G. V. (2019). Race-crime congruency effects revisited: Do we take defendants' sexual orientation into account? Social Psychological and Personality Science, 10(1), 73-81. https://doi.org/10.1177/1948550617736111Plant, E. A., \& Devine,

Plant, E. A., \& Devine, P. G. (2001). Responses to other-imposed pro-Black pressure: Acceptance or backlash? Journal of Experimental Social Psychology, 37(6), 486-501. https://doi.org/10.1006/jesp.2001.1478

Pritchard, M. E., \& Keenan, J. M. (1999). Memory monitoring in mock jurors. Journal of Experimental Psychology: Applied, 5(2), 152. https://doi.org/10.1037/1076-898X.5.2.152

Pritchard, M. E., \& Keenan, J. M. (2002). Does jury deliberation really improve jurors' memories? Applied Cognitive Psychology, 16(5), 589-601. https://doi.org/10.1002/acp.816

Rachlinski, J. J., Johnson, S., Wistrich, A. J., \& Guthrie, C. (2009). Does unconscious racial bias affect trial judges? [Undergraduate honors thesis, Cornell Law School]. Cornell Law Faculty Publications. http://scholarship.law.cornell.edu/facpub/786

Roese, N. J. (1997). Counterfactual thinking. Psychological bulletin, 121(1), 133-148. https://doi.org/10.1037/0033-2909.121.1.133

Roese, N. J., \& Olson, J. M. (1995). Outcome controllability and counterfactual thinking. Personality \& Social Psychology Bulletin, 21(1), 620-628. https://doi.org/10.1177/0146167295216008

Ruva, C. L., \& McEvoy, C. (2008). Negative and positive pretrial publicity affect juror memory and decision making. Journal of Experimental Psychology: Applied, 14(3), 226-235. https://doi.org/10.1037/1076-898X.14.3.226 
Ruva, C. L. \& Sykes, E. C. (2022). With theater, you have to be ready for anything: University response, expert testimony, and sample influence jurors’ decisions and counterfactual endorsement in a crime control theater case. Psychology, Crime \& Law, https://doi.org/10.1080/1068316X.2022.2027947

Salerno, J. M., Campbell, J. C., Phalen, H. J., Bean, S. R., Hans, V. P., Spivack, D., \& Ross, L. (2021). The impact of minimal versus extended voir dire and judicial rehabilitation on mock jurors’ decisions in civil cases. Law and Human Behavior, 45(4), 336355. https://doi.org/10.1037/lhb0000455

Salmanowitz, N. (2018). The impact of virtual reality on implicit racial bias and mock legal decisions. Journal of Law and the Biosciences, 5(1), 174-203. https://doi.org/10.1093/jlb/lsy005

Schimmack, U. (2021). The implicit association test: A method in search of a construct. Perspectives on Psychological Science, 16(2), 396-414. https://doi.org/10.1177/1745691619863798

Schuller, R. A., Kazoleas, V., \& Kawakami, K. (2009). The impact of prejudice screening procedures on racial bias in the courtroom. Law and Human Behavior, 33(4), 320328. https://doi.org/10.1007/s10979-008-9153-9

Sellers, B. G., Desmarais, S. L., \& Tirotti, M. (2014). Content and framing of male-and femaleperpetrated intimate partner violence in print news. Partner Abuse, 5(3), 259-278. DOI:10.1891/1946-6560.5.3.259

Shaw, A., Kenski, K., Stromer-Galley, J., Mikeal Martey, R., Clegg, B. A., Lewis, J. E., Folkestad, J.E., \& Strzalkowski, T. (2016). Serious efforts at bias reduction: The effects 
of digital games and avatar customization on three cognitive biases. Journal of Media Psychology, 30(1), 16-28. https://doi.org/10.1027/1864-1105/a000174

Shaw, E. V., Lynch, M., Laguna, S., \& Frenda, S. J. (2021). Race, witness credibility, and jury deliberation in a simulated drug trafficking trial. Law and Human Behavior, 45(3), 215228. https://doi.org/10.1037/lhb0000449

Shaked-Schroer, N., Costanzo, M., \& Marcus-Newhall, A. (2008). Reducing racial bias in the penalty phase of capital trials. Behavioral Sciences \& the Law, 26(5), 603-617. https://doi.org/10.1002/bsl.829

Shamon, H., \& Berning, C. C. (2020). Attention Check Items and Instructions in Online Surveys with Incentivized and Non-Incentivized Samples: Boon or Bane for Data Quality?. Survey Research Methods, 14(1), 55-77. DOI/10.18148/srm/2020.v14i1.7374

Shernock, S., \& Russell, B. (2012). Gender and racial/ethnic differences in criminal justice decision making in intimate partner violence cases. Partner Abuse, 3(4), 501-530. https://doi.org/10.1891/1946-6560.3.4.501

Skolnick, P., \& Shaw, J. I. (1997). The O. J. Simpson criminal trial verdict: Racism or status shield? Journal of Social Issues, 53(3), 503-516. https://doi.org/10.1111/00224537.00031

Smalarz, L., Madon, S., \& Turosak, A. (2018). Defendant stereotypicality moderates the effect of confession evidence on judgments of guilt. Law and Human Behavior, 42(4), 355-368. https://doi.org/10.1037/lhb0000286

Sommers, S. R. (2006). On racial diversity and group decision making: Identifying multiple effects of racial composition on jury deliberations. Journal of Personality and Social Psychology, 90(4), 597-612. https://doi.org/10.1037/0022-3514.90.4.597 
Sommers, S. R., \& Ellsworth, P. C. (2000). Race in the courtroom: Perceptions of guilt and dispositional attributions. Personality and Social Psychology Bulletin, 26(11), 13671379. https://doi-org.ezproxy.lib.usf.edu/10.1177/0146167200263005

Sommers, S. R., \& Ellsworth, P. C. (2001). White juror bias: An investigation of prejudice against Black defendants in the American courtroom. Psychology, Public Policy, and Law, 7(1), 201-229. https://doi.org/10.1037/1076-8971.7.1.201

Sommers, S. R., \& Norton, M. I. (2007). Race-based judgments, race-neutral justifications: Experimental examination of peremptory use and the Batson challenge procedure. Law and Human Behavior, 31(3), 261-273. https://doi.org/10.1007/s10979-006-9048-6

Spellman, B. A., \& Kincannon, A. (2001). The relation between counterfactual ("but for") and causal reasoning: Experimental findings and implications for jurors' decisions. Law and Contemporary Problems, 64(4), 241-264. https://doi.org/10.2307/1192297

Steblay, N.M., Hosch, H.M., Culhane, S.E., \& McWethy, A. (2006). The impact on juror verdicts of judicial instruction to disregard inadmissible evidence: A meta-analysis. Law and Human Behavior, 30(4), 469-492. https://doi.org/10.1007/s10979-006-9039-7

Su, A. (2020). A proposal to properly address implicit bias in the jury. Hastings Women's Law Journal, 31(1), 79-100. https://repository.uchastings.edu/hwlj/vol31/iss1/6

Sweeney, L. T., \& Haney, C. (1992). The influence of race on sentencing: A meta-analytic review of experimental studies. Behavioral Sciences and the Law, 10(2), 179-195. https://doi.org/10.1002/bsl.2370100204

Turner, J. C., Brown, R. J., \& Tajfel, H. (1979). Social comparison and group interest in ingroup favoritism. European Journal of Social Psychology, 9(2), 187-204. https://doi.org/10.1002/ejsp.2420090207 
U.S. District Court, District of Rhode Island. (n.d.) Unconscious Bias Jury Video. https://www.rid.uscourts.gov/unconscious-bias-jury-video

U.S District Court, Northern District of California. (n.d.). Unconscious Bias Video for Potential Jurors. https://www.cand.uscourts.gov/unconscious-bias-video-for-potential-jurors/

U. S. District Court, Western District of Washington. (2017). Unconscious Bias Juror Video. https://www.wawd.uscourts.gov/jury/unconscious-bias

Van Prooijen, J. W. (2006). Retributive reactions to suspected offenders: The importance of social categorizations and guilt probability. Personality and Social Psychology Bulletin, 32(6), 715-726. https://doi.org/10.1177/0146167205284964

Vianello, M.,\& Bar-Anan, Y. (2021). Can the implicit association test measure automatic judgment? The validation continues. Perspectives on Psychological Science, 16(2), 415421. https://doi.org/10.1177/1745691619897960

Vitriol, J. A., \& Moskowitz, G. B. (2021). Reducing defensive responding to implicit bias feedback: On the role of perceived moral threat and efficacy to change. Journal of Experimental Social Psychology, 96(8), 104165.

https://doi.org/10.1016/j.jesp.2021.104165

Wegener, D. T., \& Petty, R. E. (1997). The flexible correction model: The role of naive theories of bias in bias correction. In M. P. Zanna (Ed.), Advances in Experimental Social Psychology (Vol. 29, pp. 141-208). Academic Press. https://doi.org/10.1016/S00652601(08)60017-9

Weitzer, R., \& Tuch, S. A. (2005). Racially Biased Policing: Determinants of Citizen Perceptions. Social Forces, 83(3), 1009-1030. https://doi.org/10.1353/sof.2005.0050

West, R. F., Meserve, R. J., \& Stanovich, K. E. (2012). Cognitive sophistication does not 
attenuate the bias blind spot. Journal of Personality and Social Psychology, 103(3), 506519. https://doi.org/10.1037/a0028857

Wilson, T. D., Lindsey, S., \& Schooler, T. Y. (2000). A model of dual attitudes. Psychological Review, 107(1), 101-126. https://doi.org/10.1037/0033-295X.107.1.101

Wilson, T., Centerbar, D., \& Brekke, N. (2002). Mental contamination and the debiasing problem. In T. Gilovich, D. Griffin, \& D. Kahneman (Eds.), Heuristics and Biases: The Psychology of Intuitive Judgment (pp. 185-200). Cambridge University Press. https://doi.org/10.1017/CBO9780511808098.012

Yong, A.G., \& Pearce, S.C. (2013). A beginner's guide to factor analysis: focusing on exploratory factor analysis. Tutorials in Quantitative Methods of Psychology. 9(2), 7994. https://doi.org/10.20982/TQMP.09.2.P079 
TWO IMPLICIT BIAS REMEDIES

Table 1

Dependent Variables as a Function of Defendant and Mock-Juror Race

\begin{tabular}{|c|c|c|c|}
\hline \multicolumn{4}{|c|}{ Study 1} \\
\hline Dependent Variable & Black Defendant & White Defendant & Overall \\
\hline \multicolumn{4}{|c|}{ Murder Verdict (\% Guilty) } \\
\hline Black Juror & $92(63 \%)$ & $89(67 \%)$ & $181(65 \%)$ \\
\hline White Juror & $69(50 \%)$ & $100(71 \%)$ & $169(61 \%)$ \\
\hline Overall & $161(57 \%)$ & $189(69 \%)$ & $350(63 \%)$ \\
\hline \multicolumn{4}{|l|}{ Defendant Credibility } \\
\hline Black Juror & $40.18(13.46)$ & $39.19(13.16)$ & $39.71(13.30)$ \\
\hline White Juror & $42.51(14.80)$ & 37.07 (13.29) & $39.76(14.30)$ \\
\hline Overall & $41.31(14.15)$ & $38.10(13.25)$ & $39.73(13.80)$ \\
\hline \multicolumn{4}{|l|}{ Defendant Culpability } \\
\hline Black Juror & $14.81(5.08)$ & $15.11(5.06)$ & $14.95(5.06)$ \\
\hline White Juror & $13.36(5.38)$ & $15.60(5.05)$ & $14.49(5.32)$ \\
\hline Overall & $14.10(5.27)$ & $15.36(5.05)$ & $14.72(5.20)$ \\
\hline \multicolumn{4}{|l|}{ CF Suicide } \\
\hline Black Juror & $9.73(3.11)$ & $9.58(3.19)$ & $9.66(3.14)$ \\
\hline White Juror & $8.28(3.31)$ & $8.09(3.53)$ & $8.18(3.52)$ \\
\hline Overall & $9.02(3.28)$ & $8.81(3.45)$ & $10.85(3.36)$ \\
\hline \multicolumn{4}{|l|}{ CF Murder } \\
\hline Black Juror & $8.38(3.53)$ & $8.64(3.54)$ & $8.51(3.53)$ \\
\hline White Juror & 7.58 (3.69) & $8.61(3.16)$ & $8.10(3.46)$ \\
\hline Overall & 7.99 (3.62) & $8.63(3.35)$ & $8.30(3.50)$ \\
\hline \multicolumn{4}{|c|}{ Study 2} \\
\hline \multicolumn{4}{|c|}{ Murder Verdict (\% Guilty) } \\
\hline Black Juror & $63(47 \%)$ & $73(54 \%)$ & 136 (51\%) \\
\hline White Juror & $52(39 \%)$ & $63(45 \%)$ & $115(42 \%)$ \\
\hline Overall & $115(43 \%)$ & $136(50 \%)$ & $251(47 \%)$ \\
\hline \multicolumn{4}{|l|}{ Defendant Credibility } \\
\hline Black Juror & 47.17 (14.09) & $46.85(12.06)$ & 47.01 (13.09) \\
\hline White Juror & $48.79(12.57)$ & $47.73(11.87)$ & $48.25(12.21)$ \\
\hline Overall & $47.98(13.35)$ & $47.30(11.95)$ & $47.63(12.65)$ \\
\hline \multicolumn{4}{|l|}{ Defendant Culpability } \\
\hline Black Juror & $10.25(3.49)$ & $10.64(3.47)$ & $10.45(3.34)$ \\
\hline White Juror & $10.17(3.25)$ & $10.02(3.13)$ & $10.09(3.35)$ \\
\hline Overall & $10.21(3.37)$ & $10.33(3.31)$ & $10.27(3.33)$ \\
\hline
\end{tabular}

Note. For verdicts the frequency (percentage) voting guilty is listed. For all remaining dependent variables, we provide the mean and (standard deviation) by condition. For the sentence variable it only includes jurors finding the defendant guilty of murder (Study 1) or guilty of battery (Study 2). 
TWO IMPLICIT BIAS REMEDIES

Table 2

Study 1: Effects of Defendant Race, Juror Race, Video, and Jury Instruction on Murder Verdicts

\begin{tabular}{lcccc}
\hline & \multicolumn{2}{c}{ Murder Verdicts } \\
Conditions & $\chi^{2}$ & $d f, N$ & $p$ & $V$ \\
\hline Intercept/Model & $38.90^{*}$ & 15,554 & $<.001$ & N/A \\
Def Race & $9.00^{*}$ & 1,554 & .003 & .13 \\
Juror Race & 0.88 & 1,554 & .35 & -.04 \\
Video & 0.08 & 1,554 & .78 & .00 \\
Jury Instructions & 2.05 & 1,554 & .15 & .06 \\
Def Race x Juror Race & $3.87 *$ & 1,554 & .05 & N/A \\
Def Race x Video & 2.87 & 1,554 & .09 & N/A \\
Juror Race x Video & 0.82 & 1,554 & .36 & N/A \\
Def Race x Juror Race x Video & 0.01 & 1,554 & .91 & N/A \\
Def Race x Juror Race x Instructions & 0.48 & 1,554 & .49 & N/A \\
\hline Contrasts: Def Race x Juror Race & $\chi^{2}$ & $d f, N$ & $p$ & $V$ \\
\hline Black Juror: Black vs. White Def & 0.48 & 1,277 & .49 & .04 \\
White Juror: Black vs. White Def & $12.91^{*}$ & 1,277 & $<.001$ & .23 \\
Black Def: Black vs. White Juror & $4.92^{*}$ & 1,282 & .03 & .13 \\
White Def: Black vs. White Juror & 0.51 & 1,272 & .47 & .04 \\
Black Juror \& White Def vs. & $8.07^{*}$ & 1,269 & .004 & .17 \\
Black Def White Juror \& & 2.06 & 1,285 & .15 & .09 \\
Black Juror \& Black Def vs. & & & \\
White Juror \& White Def & & & \\
\hline
\end{tabular}

Note. Def = defendant. Effect sizes for the dichotomous verdicts are Cramer's $V$, which can only be calculated for main effects and contrasts of two means. Effect sizes for the continuous guilt rating are $\omega^{2}$ for main effects and interactions and Cohen's $d$ for contrasts. To conserve space in the table, only interactions relevant to our hypotheses or which are significant are presented. * Indicates simple effects (contrasts) are significant with the Benjamini-Hochberg (B-H) procedure to minimize the likelihood of false effects due to multiple tests (Benjamini \& Hochberg, 1995). The first 3 critical B-H values for 2way interactions are: .0167, .0333, .0500. 


\section{Table 3}

Study 1: Effects of Defendant Race, Juror Race, Video, and Jury Instruction on Defendant Culpability and Credibility

\begin{tabular}{|c|c|c|c|c|c|c|c|c|c|c|}
\hline \multirow[b]{2}{*}{ Conditions } & \multicolumn{5}{|c|}{ Defendant Culpability } & \multicolumn{5}{|c|}{ Defendant Credibility } \\
\hline & $F$ & $d f$ & $p$ & $\omega^{2}$ & $95 \% \mathrm{CI}$ & $F$ & $d f$ & $p$ & $\omega^{2}$ & $95 \% \mathrm{CI}$ \\
\hline Intercept/Model & $1.91 *$ & 15,538 & .02 & .02 & $.01, .06$ & 1.48 & 15,538 & .16 & .01 & $.00, .40$ \\
\hline Defendant Race & $8.57 *$ & 1,538 & .004 & .02 & $.00, .04$ & $7.65^{*}$ & 1,538 & .01 & .01 & $.00, .04$ \\
\hline Juror Race & 1.02 & 1,538 & .31 & .00 & $.00, .02$ & 0.01 & 1,538 & .91 & .00 & $.00, .00$ \\
\hline Video & 0.00 & 1,538 & .98 & .00 & $.00, .00$ & 0.11 & 1,538 & .74 & .00 & $.00, .01$ \\
\hline Jury Instructions & $5.57 *$ & 1,538 & .02 & .01 & $.00, .03$ & 0.12 & 1,538 & .73 & .00 & $.00, .01$ \\
\hline Def Race x Juror Race & $4.80 *$ & 1,538 & .03 & .01 & $.00, .03$ & 3.78 & 1,538 & .05 & .01 & $.00, .03$ \\
\hline Def Race x Video & 1.34 & 1,538 & .25 & .00 & $.00, .02$ & 0.06 & 1,538 & .81 & .00 & $.00, .01$ \\
\hline Juror Race x Video & 0.01 & 1,538 & .92 & .00 & $.00, .003$ & 0.01 & 1,538 & .91 & .00 & $.00, .00$ \\
\hline Video x Instructions & 1.99 & 1,538 & .16 & .00 & $.00, .02$ & 0.54 & 1,538 & .46 & .00 & $.00, .01$ \\
\hline Def Race x Juror Race x Video & 1.53 & 1,538 & .22 & .00 & $.00, .02$ & 0.36 & 1,538 & .55 & .00 & $.00, .01$ \\
\hline Def Race x Juror Race x Instruct & 2.68 & 1,538 & .10 & .00 & $.00, .02$ & 0.12 & 1,538 & .73 & .00 & $.00, .01$ \\
\hline Contrasts: Def Race x Juror Race & $t$ & $d f$ & $p$ & $d$ & $95 \% \mathrm{CI}$ & $t$ & $d f$ & $p$ & $d$ & $95 \%$ CI \\
\hline Black Juror: Black vs. White Def & -0.49 & 1,276 & .62 & .06 & $-.18, .30$ & 0.59 & 1,276 & .56 & -.07 & $-.31, .16$ \\
\hline White Juror: Black vs. White Def & $-3.61^{*}$ & 1,276 & $<.001$ & -.43 & $.19, .67$ & $3.31^{*}$ & 1,276 & .001 & .39 & $-.63,-.15$ \\
\hline Black Def: Black vs. White Juror & $2.33^{*}$ & 1,281 & .02 & -.28 & $-.51, .04$ & -1.45 & 1,281 & .15 & .17 & $-.07, .40$ \\
\hline White Def: Black vs. White Juror & -0.80 & 1,271 & .42 & -.01 & $.33,-.14$ & 1.28 & 1,271 & .20 & .16 & $-.40,-.08$ \\
\hline $\begin{array}{l}\text { Black Juror \& White Def vs. } \\
\text { White Juror \& Black Def }\end{array}$ & $-2.76^{*}$ & 1,267 & .01 & .34 & $-.58,-.10$ & 2.00 & 1,267 & .046 & -.24 & $-.00, .48$ \\
\hline $\begin{array}{l}\text { Black Juror \& Black Def vs. } \\
\text { White Juror \& White Def }\end{array}$ & -1.32 & 1,284 & .19 & .16 & $-.08, .40$ & 1.91 & 1,284 & .056 & -.23 & $-.47, .00$ \\
\hline
\end{tabular}




\section{Table 3 (continued)}

Note. Def = defendant. Effect sizes are $\omega^{2}$ for main effects and interactions and Cohen's $d$ for contrasts. To conserve space only interactions that relevant to our hypotheses or are significant are presented. * Indicates simple effects (contrasts) are significant with the Benjamini-Hochberg (BH) procedure to minimize the likelihood of false effects due to multiple tests (Benjamini \& Hochberg, 1995). The first 3 critical B-H values for 2way interactions are: .0167, .0333, .0500. The full model was tested, but only effects relevant to the hypotheses are shown, unless significant. 
TWO IMPLICIT BIAS REMEDIES

Table 4

Study 2: Effects of Juror Race, Defendant Race, Video, and Instructions on Defendant Credibility

\begin{tabular}{|c|c|c|c|c|c|}
\hline Conditions & $F$ & $d f$ & $p$ & $\omega^{2}$ & $95 \% \mathrm{CI}$ \\
\hline Intercept/Model & 1.39 & 15,523 & .15 & .01 & $.00, .05$ \\
\hline Defendant Race & 0.55 & 1,523 & .46 & .00 & $.00, .01$ \\
\hline Juror Race & 1.19 & 1,523 & .28 & .00 & $.00, .02$ \\
\hline Video & $6.27 *$ & 1,523 & .01 & .01 & $.00, .04$ \\
\hline Jury Instructions & 0.42 & 1,523 & .52 & .00 & $.00, .02$ \\
\hline Defendant Race x Juror Race & 0.05 & 1,523 & .82 & .00 & $.00, .01$ \\
\hline Defendant Race x Video & 0.26 & 1,523 & .61 & .00 & $.00, .01$ \\
\hline Juror Race x Video & 3.22 & 1,523 & .07 & .004 & $.00, .03$ \\
\hline Video x Instruction & $4.69 *$ & 1,523 & .03 & .01 & $.00, .03$ \\
\hline Defendant Race x Juror Race x Video & 0.34 & 1,523 & .56 & .00 & $.00, .01$ \\
\hline Defendant Race x Juror Race x Instruct & 0.12 & 1,523 & .73 & .00 & $.00, .02$ \\
\hline Contrasts: Juror Race x Video & $t$ & $d f$ & $p$ & $d$ & 95\% CI \\
\hline Black Juror No vs. Black Juror Yes & $*-3.02$ & 1,267 & .003 & 0.36 & $.12, .60$ \\
\hline Black Juror No vs. White Juror No & $*-2.04$ & 1,269 & .04 & 0.24 & $-.00, .48$ \\
\hline Black Juror No vs. White Juror Yes & $*-2.54$ & 1,276 & .01 & 0.30 & $.06, .54$ \\
\hline Black Juror Yes vs. White Juror No & 1.00 & 1,263 & .32 & -0.12 & $-.36, .12$ \\
\hline Black Juror Yes vs. White Juror Yes & 0.50 & 1,270 & .62 & -0.06 & $-.29, .18$ \\
\hline White Juror No vs. White Juror Yes & -0.50 & 1,273 & .61 & 0.06 & $-.17, .30$ \\
\hline Contrasts: Video x Instruction & $\mathrm{t}$ & df & $\mathrm{p}$ & d & $95 \%$ CI \\
\hline No: Gen vs. UBJ & -1.99 & 1,268 & .05 & 0.23 & $-.01,0.47$ \\
\hline Yes: Gen vs. UBJ & 1.08 & 1,269 & .28 & -0.13 & $-.37,0.11$ \\
\hline Gen: No vs. Yes & $-3.29 *$ & 1,267 & .001 & 0.39 & $.15,0.63$ \\
\hline UBJ: No vs. Yes & -0.24 & 1,270 & .81 & 0.03 & $-.21,0.27$ \\
\hline No \& Gen vs. Yes \& UBJ & $-2.23^{*}$ & 1,269 & .03 & 0.27 & $.50,0.03$ \\
\hline No \& UBJ vs. Yes \& Gen & -1.31 & 1, 268 & .19 & 0.16 & $-.08,0.40$ \\
\hline
\end{tabular}

Note. No = no unconscious bias video exposure; Yes = unconscious bias video exposure; Gen = general instructions; and UBJ = unconscious bias jury instructions. Effect sizes are $\omega^{2}$ for main effects and interactions and Cohen's $d$ for contrasts. Only interactions relevant to our hypotheses or are significant are presented. * Indicates simple effects (contrasts) are significant with the Benjamini-Hochberg (B-H) procedure to minimize the likelihood of false effects due to multiple tests (Benjamini \& Hochberg, 1995). The first 3 critical B-H values for 2-way interactions are: .0167, .0333, .0500. 
TWO IMPLICIT BIAS REMEDIES

Table 5

Study 2: Means and SDs for Defendant Credibility

\begin{tabular}{lccc}
\hline & \multicolumn{2}{c}{ Defendant Credibility } \\
UBJ Video & $\begin{array}{c}\text { General } \\
\text { Instructions }\end{array}$ & $\begin{array}{c}\text { UBJ } \\
\text { Instructions }\end{array}$ & Overall \\
\hline No Video & $44.76(13.86)$ & $47.82(12.66)$ & $46.30(13.34)$ \\
Yes Video & $49.75(11.55)$ & $48.20(12.05)$ & $48.97(11.81)$ \\
Overall & $47.26(12.98)$ & $48.01(12.34)$ & $47.64(12.65)$ \\
\hline
\end{tabular}

Note. UBJ = Unconscious Bias Jury. Mean and (standard deviation) for each condition are presented. The means for the highest-level significant interaction effect are provided (i.e., video x instruction). 


\section{Figure 1}

White Jurors: Mediation Model Examining the Direct and Indirect Effects of Defendant Race on Murder Verdicts (Study 1)

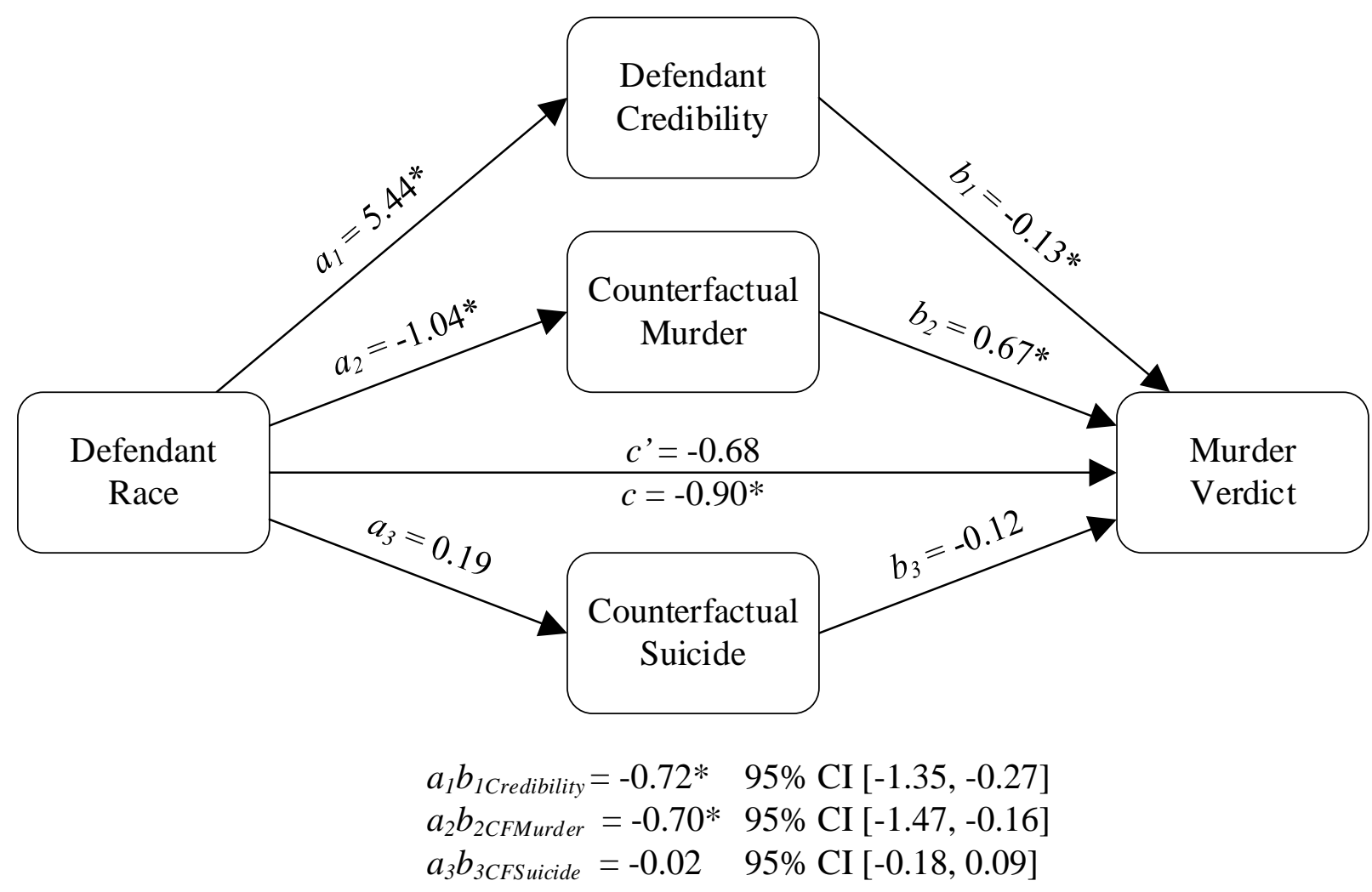

Note. The multiple mediation model (Process Model 4, Hayes, 2018) for the direct and indirect effects of Defendant Race (Black vs. White) on White jurors' murder verdicts, with the following mediators entered simultaneously: (1) defendant credibility ratings, (2) endorsement of murder counterfactuals, and (3) endorsement of suicide counterfactuals. The bootstrapping method with bias corrected confidence intervals (based on 5,000 bootstrap samples) was used. Defendant and juror race was dummy coded so that $0=$ White and $1=$ Black. Inferential statistics for parameters in model: $\left[a_{1}=5.44, t=3.22, p=.00195 \% \mathrm{CI}(2.12,8.77)\right]$; $\left[a_{2}=-1.04, t=-2.52, p=\right.$ $.0195 \% \mathrm{CI}(-1.85,0.23)]$; $\left[b_{1}=-0.13, z=-6.16, p<.001,95 \% \mathrm{CI}(-0.14,-0.09)\right] ;\left[b_{2}=0.67, z=\right.$ 6.10, $p<.001,95 \% \mathrm{CI}(0.46$, and 0.89$)] .{ }^{*} p<.05$ 